\title{
Prevalence of degree of saverity of temporomandibular join disorder based on sex and age group
}

\author{
Luciana Dewanti
}

\author{
Department of Prosthodontics Faculty of Dentistry Universitas Padjadjaran
}

\begin{abstract}
Temporomandibular joint disorders are disturbances of mastication system due to one or more component of mastication system does not properly function. The factors that play a role to this problem devided into three factors; a) predisposition factor (systemic, occlusion disturbances and psychological trouble), b) initiation factor (traumatic) and c) perpetuation factor (social behavior). These disorder are able to cause variety of symptom suck as limitedness of jaw movement, clicking, deviation locked joint, muscle pain, joint pain, jaw movement pain and pain of ear and headache. The objective of this study was to obtain information about the prevalence degree of severity of temporomandibular joint disorder, the differences of prevalence between man and woman and the different among age groups. The study was descriptive and analysis survey, done to 134 patients as experimental sample of 3-75 year old that have visited to Dental Hospital, Padjadjaran University Bandung, during February 2008. Sample consist of 57 men and 77 women were evaluated by using Helkimo Index and analisys by using $Z$ statistical proportion test to know the existence of difference prevalence degree of severity between man and woman and using chi-square test to know the difference prevalence among age groups. The result of this study show that there is highly prevalence severity of temporomandibular joint disorder $(84,33 \%)$ and significantly different on prevalence severity between man and woman and among group of ages. Conclusion can be drawn that pasients who visited to dental hospital, Padjadjaran University have higher prevalence severity of temporomandibular joint disorder where woman has higher level compare to man, and young adult group has highest either man and woman. Clicking is the most often symptom appear to man and woman.
\end{abstract}

Key words: Helkimo Index, Prevalence, Temporomandibular Joint Disorders

\section{INTRODUCTION}

Mastication system is a functional unit for chewing, swallowing, and speaking. This system consists of three main components: dentition and the supporting tissues, mandible-moving muscle and the nerve system, and temporomandibular joint system. In order to establish a normal and stable function, the three components should be in healthy condition, work normally, and perform a synchronous, balance and harmonic interaction..$^{1-3}$

Termporomandibular joint is a component of mastication system formed by temporal bone glenoid fossa and mandibular condylar process. Both left and right joint is connected to mandible by ligaments and muscles that produce bilateral

Correspondence author: Luciana Dewanti, Department of Prosthodontics Faculty of Dentistry Universitas Padjadjaran Jl. Sekeloa Selatan No. 1 Bandung, West Java-Indonesia, Tel./Fax: +6222-2504985/2532805 
articulation between one part of mandible and cranium. $^{3}$

Temporomandibular joint disorder is a mastication system disorder that involves mastication muscles, temporomandibular joint and surrounding tissue structures. This disorder is the main cause of non-dental pain in the orofacial area and many other symptoms. ${ }^{4}$

The common symptom is pain localized in mastication muscles, pre-auricular area, and temporomandinbular joint. It is worsen when chewing or performing the jaw function. Other symptoms that frequently appear are limited jaw movement, asymmetric mandible movement, and joint sound. Symptoms that are often related to bruxism and clenching are the presence of mastication muscles hypertrophy and abnormal oclusal wear. ${ }^{4}$

The cause of this disorder is complex and multifactor that can be classified into three major groups: predisposition, initiation, and perpetuation factor. The predisposition (tendency) includes general health, psychology, and the occlusal and joint structural condition. The initiation factor (initial) includes trauma and overload (parafunction). The perpetuation factor (adjusting) includes social environment, emotional problems, and several stress type and health problems. . $^{3,5-7}$

This temporomandibular joint disorder is frequently seen in community. The experiment that is established by Mardjono ${ }^{2}$ in 498 sample of 20-25 years old in Jakarta showed $79.3 \%$ of adult have joint disorder. Whereas Helkimo established a research to 321 Finland of 15-75 years old that showed $88 \%$ of the sample have joint disorder with one or more symptoms. ${ }^{8-9}$

Research about the prevalence of temporomandibular joint disorder severity level has been performed by several researchers and the results were vary according to the index, ananestic dysfunction or clinical dysfunction index..$^{9,10}$ Considering the gender distribution, many researchers stated that the majority (70$90 \%$ ) of joint disorder was founded in women ${ }^{8}$, but other experiments stated that there was no significant different in joint disorder case between man and woman. ${ }^{2,9,10}$

There is also exist different result between each age group in the distribution, just like in
Mardjono experiment. ${ }^{2}$ The experiment stated that age group of 41-55 years old experience the most frequent joint disorder. Whereas Koidis founded that the biggest group is group of $<30$ years old. ${ }^{11}$

Therefore, due to the fact that the differences and the experiment performed in Indonesia only underlined the cause, symptom and treatment, but not the temporomandibular joint disorder severity level prevalence in all age groups, the author would like to observe the temporomandibular joint disorder severity level prevalence based on gender and age group among Oral and Dental Hospital Faculty of Dentistry Universitas Padjadjaran Bandung/RSGM FKG UNPAD patients.

\section{METHODS}

The research was performed using descriptive and analytical survey approach. The data were collected by using questionnaires, as well as clinical examination of the subjects. The data collected were then assessed by Helkimo's clinical dysfunction index ${ }^{8,9}$, then the analysis of prevalence level of temporomandibular joint dysfunction were performed based on sex and age.

Population in this research is all of the patients who visit Oral and Dental Hospital Faculty of Dentistry Universitas Padjadjaran Bandung/ RSGM FKG UNPAD in February 2008 and meet the criteria: (1) They did not have unstable teeth, dental gap, bleeding gum, trigeminal neuralgia, pericoronitis, pulpitis, ear inflammation, sinus or nose inflammation, sore throat and rheumatic which the symptoms like temporomandibular disorder symptoms. ${ }^{12}(2)$ They were not taking any painkiller or analgesics.

Samples were taken by random sampling method from the populations. Instruments and material for the research are: dental chair, mirror, tweezers, explorer, masker and gloves, stethoscope, ruler, stationery, questionaire sheet (personal data and medical history), clinical examination sheet.

\section{The steps of the research}

Patients who visit Oral and Dental Hospital Faculty of Dentistry Universitas Padjadjaran Bandung/RSGM FKG UNPAD were first examined in 


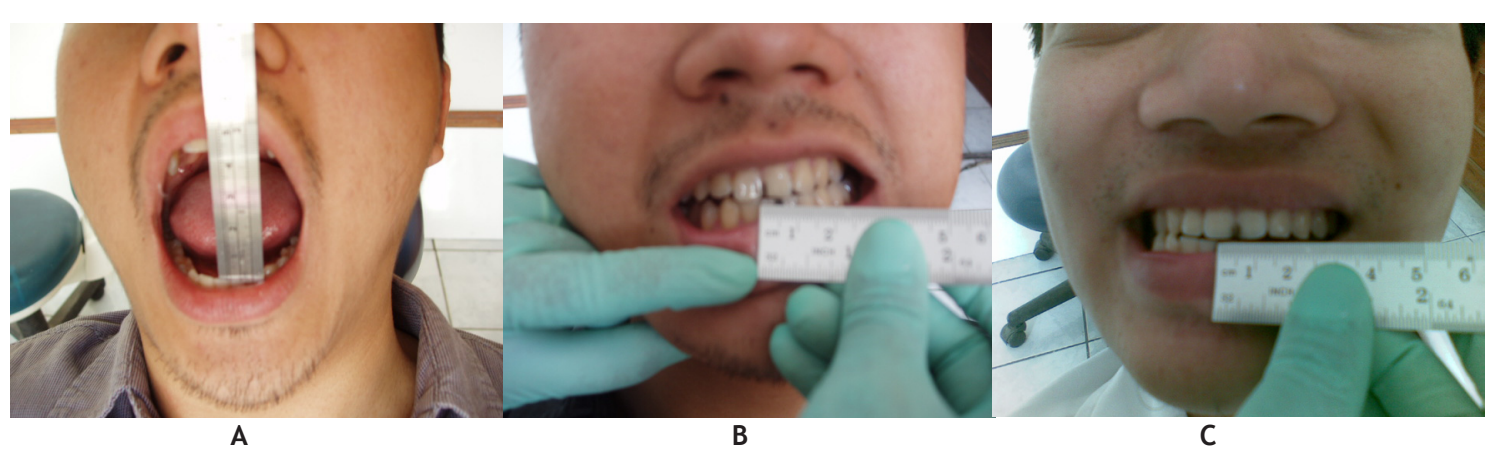

Figure 1. The examination of movement restriction: A. Vertical; B. Left horizontal; C. Right horizontal.

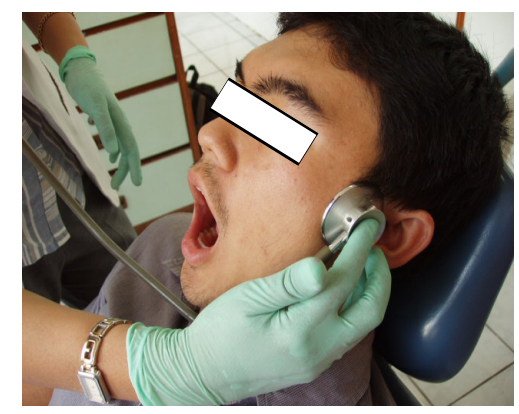

Figure 2. The examination of joint noise (clicking).

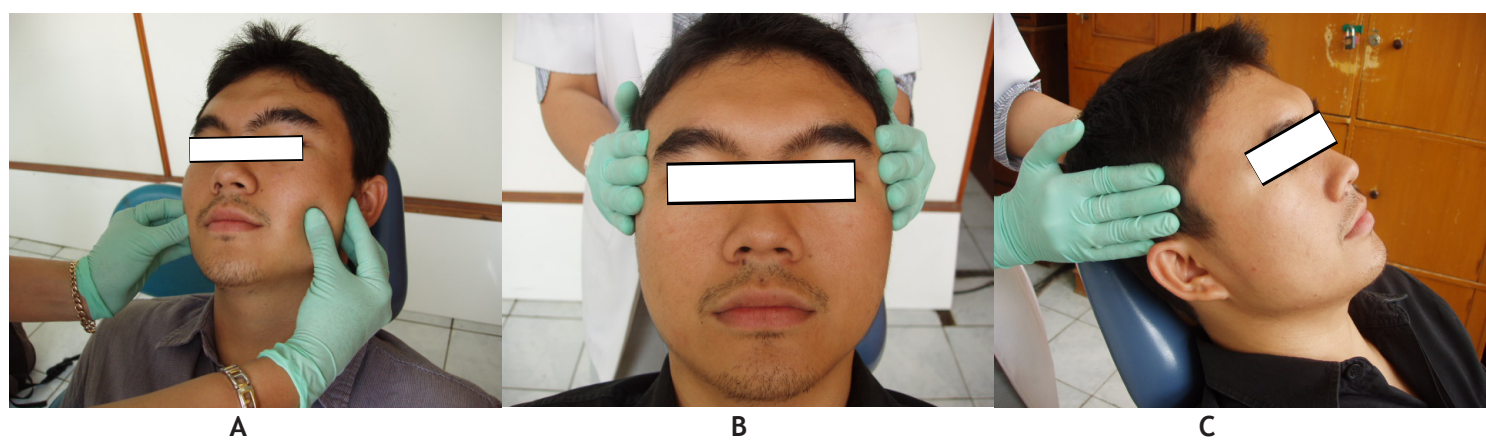

Figure 3. Muscle examination: A. Masseter; B. Temporal regio anterior; C. Temporal regio posterior.

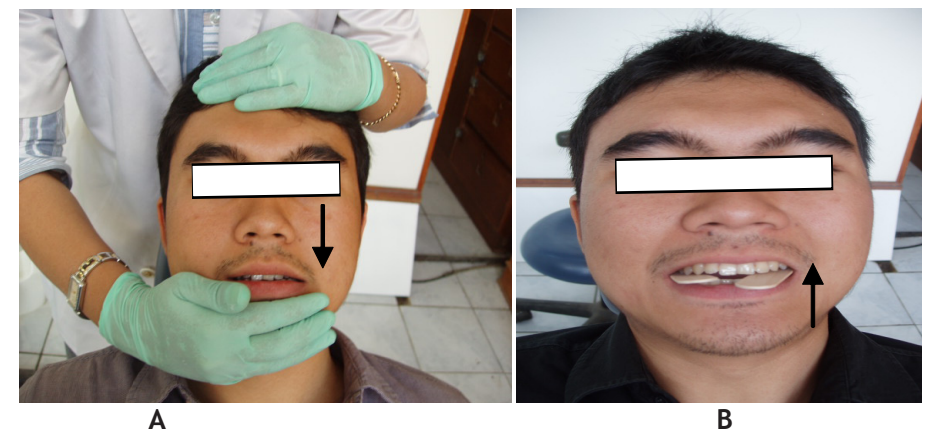

Figure 4. Muscle examination: A. Inferior lateral pterygoid; B. Superior lateral pterygoid and medial pterygoid

* The arrow indicates jaw movement.

the screening department to have thorough dental examination, then they were given a questionnaire sheet asking about their personal data and medical history.

Questionnaires which have been filled by the patients were then assessed by the research. If the result meet the criteria of research subject, the patient were asked to fill letter of approval to be research subject. Patients then were asked to sit in dental unit, then they were examined 


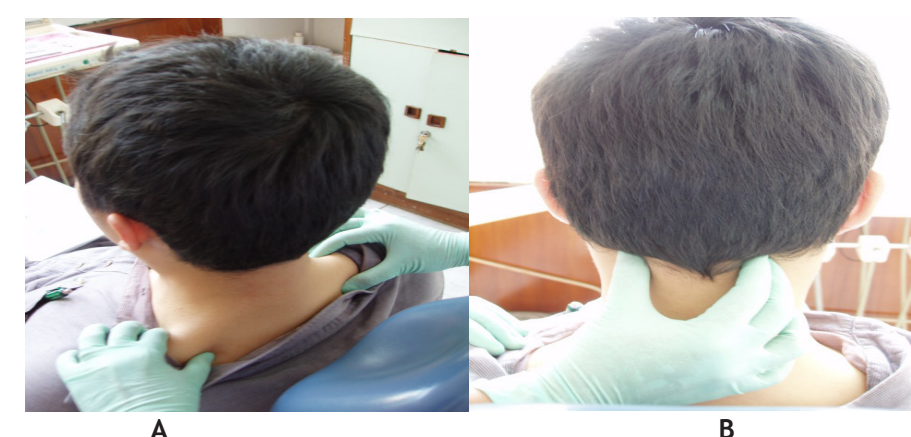

Figure 5. Muscle examination: A.Traphesius; B. Splenius.

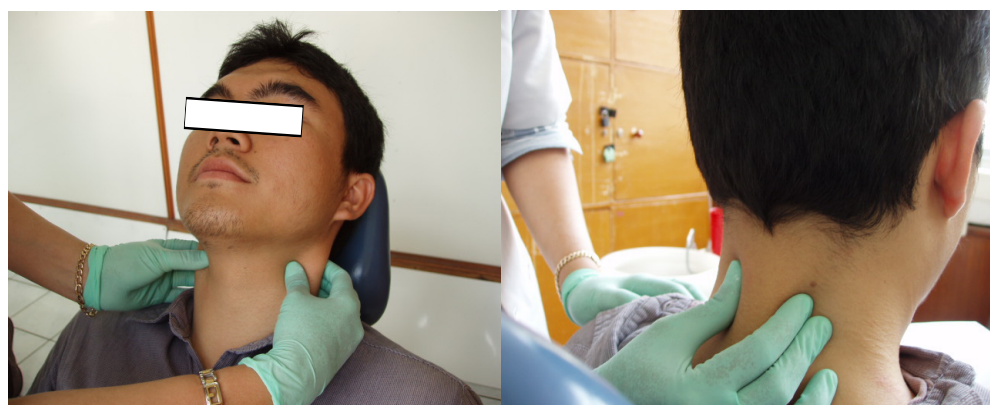

Figure 6. Muscle examination: A. Sternocleidomastoid; B. Servicalis.

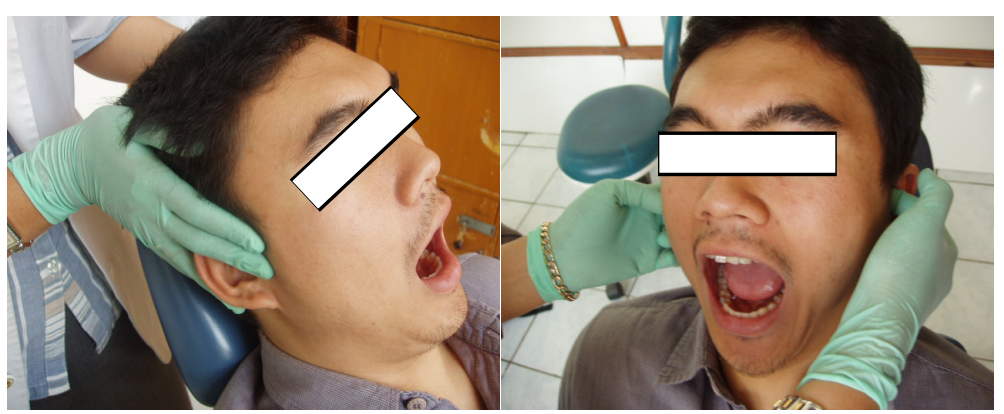

Figure 7. Joint examination: A. Lateral palpation; B. Posterior palpation.

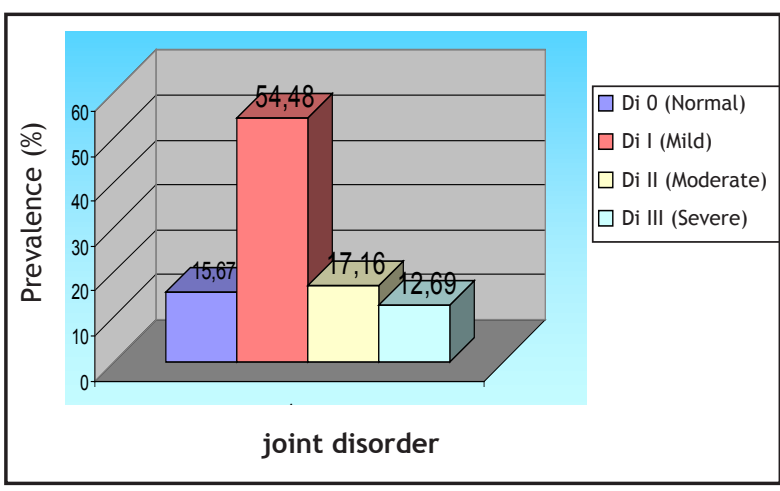

Figure 8. Temporomandibular joint disorder severity level prevalence (Normal, mild, moderate, and severe).

to find if they have the five clinical symptoms of temporomandibular joint disorder. 8,9

The examination of jaw movement was

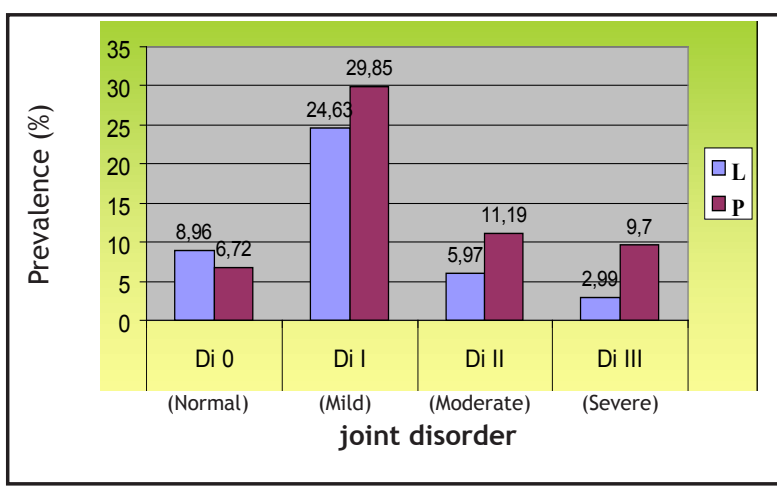

Figure 9. Temporomandibular joint disorder severity level based on gender (Normal, mild, moderate, and severe).

performed to find out whether there is jaw movement restriction. The examination included the measurement of the range of vertical and 


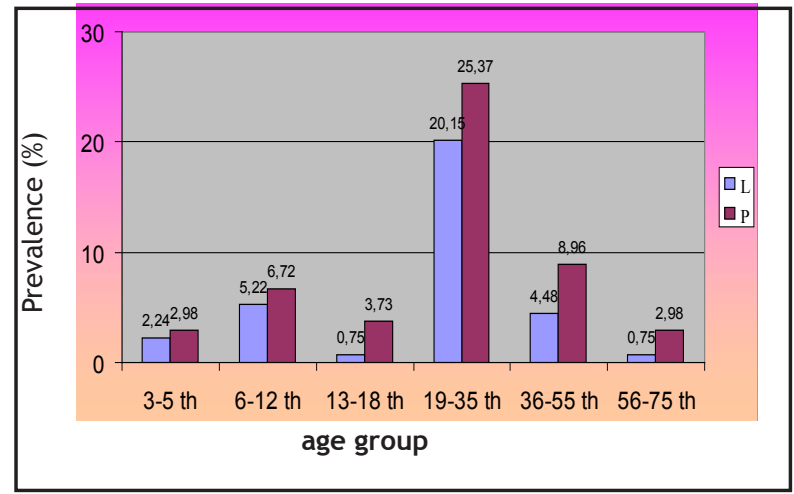

Figure 9. Temporomandibular joint disorder severity level based on age group (Normal, mild, moderate, and severe).

Table 1. Temporomandibular joint disorder severity level analysis based on gender.

\begin{tabular}{cccccccc}
\hline & N & Normal & Disorder & Prevalence & Z-count & Z-table & Properties \\
\hline Men & 57 & 12 & 45 & 33.58209 & 2.70 & 1.96 & Sign \\
Women & 77 & 9 & 68 & 50.74627 & & & \\
Total & 134 & 21 & 113 & & & & \\
\hline
\end{tabular}

Table 2. Analysis of joint disorder severity level based on age group.

\begin{tabular}{cccc}
\hline Age group & Observed $\mathbf{N}$ & Expected $\mathbf{N}$ & Residual \\
\hline Play group (3-5) & 7 & 18.8 & -11.8 \\
Elementary School (6-12) & 16 & 18.8 & -2.8 \\
Teen (13-18) & 6 & 18.8 & -12.8 \\
Adolescence (19-35) & 61 & 18.8 & 42.2 \\
Edult (36-55) & 18 & 18.8 & -8 \\
Elderly 56-75 & 5 & 18.8 & -13.8 \\
Total & 113 & & \\
\hline
\end{tabular}

horizontal mouth opening. To examine vertical range, patients were instructed to open their mouth as wide as possible, then the distance between incisal edge of maxillary and mandible central incisive were measured. The results were then recorded in clinical examination sheet (Fig 1 A). ${ }^{13}$

To examine left horizontal jaw movement, the patients were instructed to move their jaws as wide as they can to the left, then it was measured by drawing a line in upper central incisivus diameter, to the diameter of lower central incisivus (Fig.1 B), and the contrary were performed to examine right horizontal jaw movement (Fig $1 \mathrm{C}) .{ }^{13}$ The results were then recorded in clinical examination sheet.

The examination of joint function were performed to find out whether there are noise in the joints, deviation, and locked joint. The examination were performed by instructing the patients to open and close their mouth, with stethoscope that were put in the joint area, then the operator listened to the noise of the joint (Fig. 2). ${ }^{13}$ The results were then recorded in clinical examination sheet.

The examination of deviation was performed by instructing the patients to open and close the mouth. Then the operator observed the pattern of mouth opening, as well as observed the direction of deviation whether it was to the right or left. ${ }^{13}$ Besides, operator also observed whether the patients suffered joint lock in mouth opening. The results were then recorded in clinical examination sheet.

The examination of the muscles was performed to see if there were muscle pains. The examination included masseter, temporal, pterygoid lateral superior, pterygoid lateral 
Table 3. Prevalence of temporomandibular joint disorder symptom severity level on man.

\begin{tabular}{|c|c|c|c|c|c|c|c|c|}
\hline \multirow{2}{*}{ Symptoms } & \multicolumn{6}{|c|}{ Age group } & \multirow{2}{*}{ Total } & \multirow{2}{*}{$\%$} \\
\hline & 3-5 & $6-12$ & $13-18$ & $19-35$ & $36-55$ & $56-75$ & & \\
\hline \multicolumn{9}{|l|}{ Limited jaw movement includes: } \\
\hline Limited vertical movement & 3 & 4 & - & 3 & 1 & - & 11 & 6,63 \\
\hline \multirow[t]{2}{*}{ Limited horizontal movement } & 2 & 1 & 1 & 17 & 2 & - & 23 & 13,85 \\
\hline & & & & & & & & 20,48 \\
\hline \multicolumn{9}{|l|}{ Limited joint function includes: } \\
\hline Clicking & - & 2 & - & 16 & 4 & 1 & 23 & 13,85 \\
\hline Deviation & - & 1 & - & 12 & 4 & - & 17 & 10,24 \\
\hline \multirow[t]{2}{*}{ Locking jaw } & - & - & - & 1 & - & - & 1 & 0,60 \\
\hline & & & & & & & & 24,69 \\
\hline \multicolumn{9}{|l|}{ Muscle pain includes: } \\
\hline Masseter muscle pain & - & - & - & 11 & 2 & - & 13 & 7,83 \\
\hline Temporal muscle pain & - & - & - & 6 & 3 & - & 9 & 5,42 \\
\hline Pterygoid Lateral muscle pain & - & - & - & 4 & 2 & - & 6 & 3,61 \\
\hline Pterygoid Medial muscle pain & - & - & - & 5 & & - & 8 & 4,82 \\
\hline Traphesius muscle pain & - & - & - & 16 & 5 & 1 & 22 & 13,25 \\
\hline Splenius muscle pain & - & - & - & 3 & 4 & 1 & 8 & 4,82 \\
\hline Sternocleidomastoid muscle pain & - & - & - & 3 & - & - & 3 & 1,81 \\
\hline \multirow[t]{2}{*}{ Cervical muscle pain } & - & - & - & 9 & 3 & - & 12 & 7,23 \\
\hline & & & & & & & & 48,79 \\
\hline \multicolumn{9}{|l|}{ Temporomandibular joint pain } \\
\hline $\begin{array}{l}\text { include: } \\
\text { Lateral Palpation pain }\end{array}$ & - & - & - & 1 & - & - & 1 & 0,60 \\
\hline \multirow[t]{2}{*}{ Posterior Palpation pain } & - & 1 & - & 1 & 2 & - & 4 & 2,41 \\
\hline & & & & & & & & 3,01 \\
\hline \multicolumn{9}{|l|}{ Jaws movement pain includes: } \\
\hline Vertical movement pain & - & - & - & 2 & 1 & - & 3 & 1,81 \\
\hline Horizontal movement pain & - & - & - & 1 & 1 & - & 2 & 1,20 \\
\hline Chewing movement pain & - & - & - & - & - & - & 0 & 0,00 \\
\hline \multirow[t]{2}{*}{ Swallowing movement pain } & - & - & - & - & - & - & 0 & 0,00 \\
\hline & & & & & & & & 3,01 \\
\hline Total & 5 & 9 & 1 & 111 & 37 & 3 & 166 & 100,00 \\
\hline$\%$ & 3 & 5,42 & 0,60 & 66,87 & 22,29 & 1,81 & 100,00 & - \\
\hline
\end{tabular}

inferior, pterygoid medial, trapezius, splenius, sternocleidomastoid and servical muscles examination. The examination of masseter muscle were performed by directly palpating the masseter muscles (Fig. 3 A). ${ }^{13}$ Patient's response were then recorded in the clinical examination sheet.

Temporal muscle examination were performed by directly palpating the regio anterior and posterior of temporal muscle (Fig. $3 \mathrm{~B}, \mathrm{C}$ ). The examination of lateral and medial pterygoid muscle was performed by functional manipulation. Functional manipulation of inferior lateral pterygoid muscle were performed by asking the patients to make protrusive movement against resistance movement (Fig 4. A), ${ }^{13}$ meanwhile functional manipulation of superior lateral pterygoid muscle and medial pterygoid muscle were performed by asking the patients to clench or to bite the separator strongly (Fig. $4 \mathrm{~B}, \mathrm{C}$ ). ${ }^{13}$ If this muscles is the source of pain, the movement will cause the pain.

The examination of trapezius muscle was performed by palpating from the backside of sternocleidomastoid muscle, aside and down to the shoulder (Fig. 5 A). Splenius muscle examination were performed by palpating the splenius muscle attachment in the cranium, i.e. posterior area of sternocleidomastoid muscle (Fig 5 B). ${ }^{13}$

The examination of sternocleidomastoid muscle ans servical muscle were performed by 
Table 4. Temporomandibular joint severity level prevalence in women.

\begin{tabular}{|c|c|c|c|c|c|c|c|c|}
\hline \multirow{2}{*}{ SYMPTOMS } & \multicolumn{6}{|c|}{ AGE GROUP } & \multirow{2}{*}{ Total } & \multirow{2}{*}{$\%$} \\
\hline & $3-5$ & $6-12$ & 13-18 & 19-35 & $36-55$ & $56-75$ & & \\
\hline \multicolumn{9}{|l|}{ Limited jaw movement includes: } \\
\hline Limited vertical movement & 2 & 6 & 1 & 6 & 1 & - & 16 & 4,66 \\
\hline \multirow[t]{2}{*}{ Limited horizontal movement } & 2 & 5 & 2 & 13 & 7 & 1 & 30 & 8,75 \\
\hline & & & & & & & & 13,41 \\
\hline \multicolumn{9}{|l|}{ Limited joint function includes: } \\
\hline Clicking & 1 & 2 & 3 & 29 & 11 & 3 & 49 & 14,29 \\
\hline Deviation & - & 2 & 3 & 22 & 6 & 2 & 35 & 10,20 \\
\hline \multirow[t]{2}{*}{ Locking jaw } & - & - & - & - & - & - & - & 0,00 \\
\hline & & & & & & & & 24,49 \\
\hline \multicolumn{9}{|l|}{ Muscle pain includes: } \\
\hline Masseter muscle pain & - & - & 1 & 17 & 5 & - & 23 & 6,71 \\
\hline Temporalis muscle pain & - & - & 2 & 12 & 6 & - & 20 & 5,83 \\
\hline Pterygoid Lateral muscle pain & - & - & 1 & 8 & 2 & - & 11 & 3,21 \\
\hline Pterygoid Medial muscle pain & - & 1 & 2 & 11 & 5 & - & 19 & 5,54 \\
\hline Traphesius muscle pain & - & 1 & 3 & 30 & 12 & 3 & 49 & 14,29 \\
\hline Splenius muscle pain & - & - & - & 8 & 2 & - & 10 & 2,92 \\
\hline Sternocleidomastoid muscle pain & - & - & 1 & 7 & 7 & 2 & 17 & 4,96 \\
\hline \multirow[t]{2}{*}{ Cervical muscle pain } & - & - & 3 & 19 & 8 & 2 & 32 & 9,33 \\
\hline & & & & & & & & 52,79 \\
\hline \multicolumn{9}{|l|}{$\begin{array}{l}\text { Temporomandibular joint pain } \\
\text { include: }\end{array}$} \\
\hline Lateral Palpation pain & - & - & - & 8 & 1 & - & 9 & 2,62 \\
\hline \multirow[t]{2}{*}{ Posterior Palpation pain } & - & - & 2 & 11 & 1 & - & 14 & 4,08 \\
\hline & & & & & & & & 6,70 \\
\hline \multicolumn{9}{|l|}{ Jaws movement pain includes: } \\
\hline Vertical movement pain & - & - & - & 5 & - & - & 5 & 1,46 \\
\hline Horizontal movement pain & - & - & - & 1 & 1 & - & 2 & 0,58 \\
\hline Chewing movement pain & - & - & - & 2 & - & - & 2 & 0,58 \\
\hline \multirow[t]{2}{*}{ Swallowing movement pain } & - & - & - & - & - & - & - & 0,00 \\
\hline & & & & & & & & 2,62 \\
\hline Total & 5 & 17 & 24 & 209 & 75 & 13 & 343 & 100,00 \\
\hline$\%$ & 1,46 & 4,96 & 7,00 & 60,93 & 21,87 & 3,79 & 100,00 & - \\
\hline
\end{tabular}

palpating the muscles, as shown in Figure 6 Aand B. ${ }^{13}$ Temporomandibular joint examination is performed to examine the present of joint pain include condyle lateral aspect palpation that located $10 \mathrm{~mm}$ in front external acusticus meatus (Fig. 7A) and condyle posterior aspect palpation by pressing pointy finger on meatus acusticus externus and palpated anteriorly (Fig. 7 B). Palpation is performed when the mandible not able to move dynamically and when the finger positioned on joint area, ask the patient to relax and give moderate pressure on the joint area, and examine the patient facial expression, then ask about any symptom that he/she felt and write it down in the examination sheet.
Jaw-movement examination is performed to examine the present of pain during movement by instructing the patient to open and close his/her mouth, moving the jaw to the left and right, chewing, and swallowing. Then record the response in the clinical examination sheet. After examined and the result recorded, the patient is asked to continue the treatment needed.

\section{RESULT}

To find out the severity level prevalence of temporomandibular joint disorder based on gender and age, a study is performed to patient of Oral and dental Hospital FKG UNPAD on February 2008. 
The sample consists of 134 individuals include 57 men $(42.55 \%)$ and 77 women (57.46\%). From the initial study performed in one week, patient who come and fills the criteria is 177 individuals. So in the February, it is assumed that the population is fourfold, that is 708 individuals.

Figure 8. presents the result of temporomandibular joint disorder severity level prevalence descriptively. Of the entire sample, $15.67 \%$ experience no disorder, and $84.33 \%$ experience the disorder from mild to severe, i.e. 73 patients $(54.84 \%)$ have mild disorder, 23 patients $(17.16 \%)$ have moderate disorder and $12.69 \%$ have severe disorder.

Result about temporomandibular joint disorder severity level prevalence based on gender is descriptively presented in Fig 9. According to the research, women show higher prevalence than men, i.e. $29.85 \%$ have mild disorder, 11.19 have moderate disorder, and $9.70 \%$ have severe disorder and group that experience no disorder is lower, that is $6.72 \%$.

Table 1 above shows that there are statistically significant differences between men and women It means that men prevalence of $33.58 \%$ is significantly different from women prevalence of $50.57 \%$. This shows that frequency of temporomandibular joint disorder in women is higher than men.

The research result about the prevalence of temporomandibular joint disorder severity level based on group age is descriptively seen in the Fig 10 , where the age group of 56-57 years old has the lowest prevalence (3.73\%) and age group of 19-35 years old (adolescence) has the highest prevalence either in men $(20.15 \%)$ or women, $(23.37 \%)$.

Table 2 above shows that there is a statistically significant different in the age group, And it is shown that the residual value in the adolescence group (19-35 years old) is 42.2 . The value is the highest in the age group category, so it can be concluded that the adolescence is the group with the highest prevalence of temporomandibular joint disorder.

The research result about prevalence of temporomandibular joint disorder severity level is descriptively shown in the Table 3. The table above shows three most often symptoms in men, i.e. clicking (13.85\%), limited horizontal movement (13.85\%), and trapezius muscle pain (13.25\%), and chewing and swallowing pain.

In women, the prevalence of temporomandibular joint disorder symptom is descriptively shown in the Table 4 where there are three most often symptoms, i.e. clicking (14.29\%), trapezius muscle pain $(14.29 \%)$, and deviation (10.20\%). Locking and swallowing pain are not founded in the research. From the Table 2 and 3, the most symptoms is happened in the age group of 19-35 years old (adolescence), either in men $(66.87 \%)$ or women $(60.93 \%)$.

\section{DISCUSSION}

It is shown in the Fig 8. that from overall sample, only $15.67 \%$ patients who do not experience the disorder, whereas the others 84.33 patients experience the disorder of mild-severe level. If compared with other prior experiments, such as Helkimo ${ }^{8,9}$ or Otuyemi ${ }^{10}$, there no significant different in the severity level percentage, Helkimo has $8 \%$ samples with clinical disorder and Otuyemi has $62.8 \%$ samples with the highest percentage on mild disorder and the lowest percentage in the severe disorder. From theses results, it can be concluded that the temporomandibular joint disorder case has a high prevalence number, where nationality does not affect possibility of the appearance.

Severity level prevalence based on gender shows that there is a statistically significant different between men and women as shown in the Fig 9 , i.e. the severity level prevalence in women is $50.75 \%$ and in men is $33.58 \%$. The result meets with many other prior researchers, such as Agerberg ${ }^{14}$, Butler ${ }^{15}$, Takada ${ }^{16}$, Koidis ${ }^{11}$ and Lunden ${ }^{17}$. They founded that women has higher prevalence of temporomandibular joint disorder case than men.

This is caused by the different of physiology and psychology factors between men and women. Concerning physiology, women has better tolerant and pain threshold than men. ${ }^{11}$ The psychology factor is very important, because feelings of worried, depression, anger, and emotion are common in women and can result in muscle tension $^{17}$, constriction, and oxygen reduction in the blood vessel and substance releasing that can produce pain. ${ }^{11}$ And it is also said that women frequently seek out treatment for joint 
disorder. $^{2,17}$

In this experiment, the severity level prevalence based on age group shows that there is a significant different between each groups, where the adolescence (19-35 years old) has the highest prevalence, either in men (20.1\%) or in women (25.37\%). The result is similar to Otuyemi ${ }^{10}$ experiment on 308 adolescence samples of 17-32 years old in Nigeria with $62.5 \%$ of temporomandibular joint disorder case. The high percentage is also founded in Mardjono ${ }^{2}$ experiment on sample of 41-45 years old with 93.6\% of temporomandibular joint disorder case and Koidis experiment on sample of $<30$ years old with $64.5 \%$ of temporomandibular joint disorder case. $^{11}$

This is resulted because in adolescence group, the stress increasing and psychological problem related to economical condition is very common. ${ }^{17}$ And more often as a result of tooth removal that is not followed by immediately replacement. This could gives rise to tooth position change that located close to diastema, so the tooth become extruded and inclined and every time the mandible move, it collide with the opposite tooth. ${ }^{2}$ These collisions could result in microtrauma in temporomandibular joint, where unnecessary force produced every time the teeth contacts each other, such as drawer, rotation, or torque on temporomandibular joint. If this happens continuously, then it will eventually produce temporomandibular joint disorder. ${ }^{12}$

The temporomandibular joint disorder symptom based on gender can be seen in Table 2 and 3. According to the tables, clicking or sound of joint is a common symptom for the joint disorder patient, either in men (13.85\%) or women (14.29\%). The experiment performed by Agerberg and Carlsoon ${ }^{8}$ on 1,215 women samples of 15-74 years old and Hasson and Nilner on 1.069 patient of 2-65 years old show similar results for clicking, i.e. $39 \%$ and $65 \% .^{18}$

Clicking or joint sound is resulted from condylus and disc in-coordination where disc (disc displacement) moves interiorly, so when the condylus crossing the disc thick-area, clicking is produced. ${ }^{12}$ Clicking can be heard by put the stethoscope (auscultation) on the joint area, where condylus suddenly slip/hop. ${ }^{2}$ The clicking is an initial symptom of temporomandibular joint disorder before severe symptoms appear. ${ }^{19}$ This is the reason why clicking is the most common symptom in this experiment and other experiments.

Trapezius muscle pain is the second common symptom in women (14.29\%) and the third in men (13.25\%). According to Mc Neill, pain in the neck and shoulder muscles (include trapezius muscle) is estimated about $40 \%$ of all chronic joint function disorder case. The muscles in neck and shoulder are not the main muscle in the mandible movement ${ }^{12}$, but have important role in the mandible function because there is a connection between this muscle pain and patient work load or body position. ${ }^{20} \mathrm{In}$ this experiment, there was a sample who work as star observer, work in building store so he has to carry cement on his back, dentist, and secretary who has to utilize a computer continuously. And there was also patient with head position more forward than his back, so resulted in trauma/ workload to his trapezius muscle. As said before, inappropriate body position or continuously trauma on one of body organ, especially muscles around head, neck, and shoulder can result in muscle fascia function disorder that causes other organ disorder such as joint. ${ }^{20}$

Even tough there are differences of sample amount, the age group distribution and measuring method, but the result achieved is quite similar to the prior experiments. Such as Clark ${ }^{21}$, Helkimo ${ }^{22}$ clinical dysfunction index has many deficiency, i.e. not mention how big the force given to the muscle or joint, not using clicking/joint sound severity assessment method, not grouping the disorders according to the cause and very depends on the researcher competence and the patient honesty in answering the question. Song also stated that Helkimo clinical dysfunction index can not differentiate the disorder of joint, muscle or both and not sufficiently sensitive to measure any little change in every severity level. ${ }^{22}$

Because this experiment is still lack of system index, it is needed to perform experiment using index system that can improve the Helkimo index system, such as RDS (Research Diagnostic Criteria) index system. RDC can differentiate the disorder according to the cause, so the result achieved can be accurately apply for more appropriate treatment plan. 


\section{CONCLUSION}

Oral and Dental Hospital Faculty of UNPAD patients have high prevalence number of temporomandibular joint disorder severity level, that is $84.33 \%$, where the bigger percentage of $54.48 \%$ experience mild disorder. The prevalence of temporomandibular joint disorder severity level based on gender shows that women significantly has higher prevalence than men and the prevalence based on age group shows that adolescence group significantly has highest prevalence, either in women or men. The temporomandibular joint disorder symptom prevalence shows three most common symptoms in men, that are clicking, limited horizontal movement, trapezius pain, and three most common symptoms in women that are clicking, trapezius pain, and deviation.

\section{SUGGESTION}

Considering the high prevalence of temporomandibular joint disorder severity level, it is needed to give extra attention to the preventive action toward the disorder, causes and symptoms, especially on the gender and groups who has highest prevalence. It is suggested to provide facilitations needed by the patients, such as physiotherapy tools, medication, and material and tools to make an oclusal splin so the patient can be treated immediately and directly. And it is necessary to perform an experiment about temporomandibular joint disorder using other index that can differentiates the disorder according to the cause, so a direct-diagnostic result can be achieved and the treatment can be established appropriately.

\section{REFERENCES}

1. Ash MM, Ramfjord SP. Occlusion. $4^{\text {th }}$ ed. Philadelphia: W.B. Saunders Co.; 1995. p. 5089.

2. Mardjono D. Hubungan antara pola mengunyah kebiasaan yang salah dengan disfungsi sendi temporomandibula pada orang dewasa di Jakarta. Disertasi. Bandung: Universitas Padjadjaran; 1989.

3. Pertes RA, Gross SG. Clinical management of temporomandibular disorders and orofacial pain. Chicago: Quintessence Publishing Co. Inc.; 1995. p. 1-9,60-2.

4. McNeill C. Temporomandibular disorders. $2^{\text {th }}$ ed. Carol Stream: Quintessence Publishing Co. Inc.; 1993. p. 11-32.

5. Carlsson GE, Magnusson T. Management of temporomandibular disease in general dental practice. Chicago: Quintessence Publising Co. Inc.; 1999. p. 19-23.

6. Kaplan AS, Assael LA. Temporomandibular disorder: Diagnosis and treatment. Philadelphia: W.B. Saunders Co.; 1991. p. 2 10,40-7,284-91.

7. McNeill C. Management of temporomandibular disorders: concept and controversies. J Prosthet Dent 1997;77:510-21.

8. Helkimo M. Epidemiological surveys of dysfunction of the masticatory system. In: Zarb G, Carlsson G, editors. Temporomandibular joint function and dysfunction. St. Louis: CV Mosby Co.; 1979. p. 175-92.

9. Helkimo M. Studies on function and dysfunction of the masticatory system. Part III. Analysis of anamnestic and clinical recording of dysfunction with the aid of indices. J Swed Dent 1974;67:165-81.

10. Otuyemi OD, Owotade FJ, Ugboko VI, Ndukwe $\mathrm{KC}$, Olusile OA. Prevalence of signs and symptoms of temporomandibular disorders in young nigerian adults. British $\mathrm{J}$ Orthod 2000;27(1):61-6.

11. Koidis PT, Zarifi A, Grigoriadou E, Garefis P. Effect of age and sex on craniomandibular disorders. J Prosthet Dent 1993;69:93-101.

12. Dawson PE. Evaluation, diagnosis and treatment of occlusal problem. St. Louis: C.V. Mosby Co.; 1974. p. 16-34.

13. Okeson JP. Management of temporomandibular disorders and occlusion. $6^{\text {th }}$ ed. Philadelphia: CV Mosby Inc.; 2008.

14. Shore NA. Temporomandibular joint dysfunction and occlusal equilibration. $2^{\text {nd }}$ ed. Philadelphia: J.B. Lippincott Co.; 1976. p. 120-24.

15. Butler J, Folke L. A descriptive survey of signs and symptoms associated with the myofascial pain-dysfunction syndrome. In: Zarb G, Carlsson G, editors. Temporomandibular joint function and dysfunction. St. Louis: CV Mosby Co.; 1979. p. 175-92. 
16. Takada K, Yoshimura Y. Clinical study of the temporomandibular joint disturbances. In: Zarb G, Carlsson G, editor. Temporomandibular joint function and dysfunction. St. Louis: CV Mosby Co.; 1979. p. 175-92.

17. Lunden TF, Levitt SR, McKinney MW. Discriminative ability of the TMJ scale: Age and gender differences. J Prosthet Dent 1986;56:84-92.

18. Hansson T, Nilner $M$. A study of the occurrence of symptoms of deseases of the temporomandibular joint, masticatory musculature and related structures. J Oral Rehabil 1975;2:313-25.

19. Sarnat BG, Laskin DM. The temporomandibular joint: A Biological basis for clinical practice. $2^{\text {th }}$ ed. Philadelphia: W.B. Saunders Co.;1992. p. 237-46.

20. Uppgaard RO. Taking control of TMJ. Oakland: New Harbinger Publications Inc.; 1999. p. 1333

21. Clark GT, Delcanho RE, Goulet JP. The utility and validity of current diagnostic procedures for defining temporomandibular disorder patients. Adv Dent Res 1993;7(2):97-112.

22. Song Y. Study on the improvement of the craniomandibular index in the assessment of craniomandibular disorders. J Korean Academy of Oral Med 1995;15:45-56. 